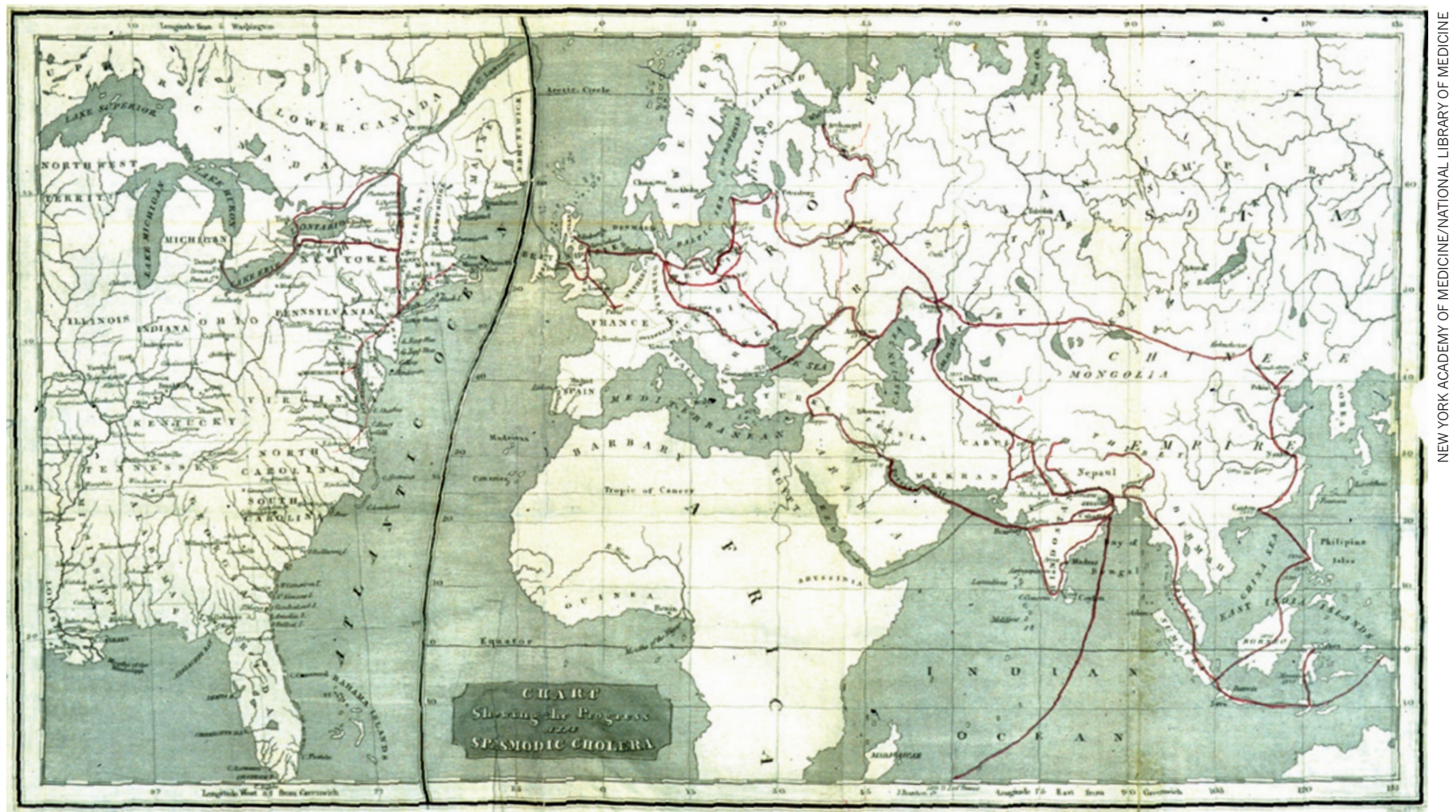

Red lines on an 1832 map show how cholera spread from India to Europe and North America along major trade routes.

\title{
Charting the spread of sickness
}

\section{A history of disease mapping shows that despite technological developments, little has changed in 500 years, finds Andy Tatem.}

\section{CC} ll-clothed, ill-fed, uncleanly in their persons and dwellings, subsisting chiefly on indigestible and unwholesome foods and in the habit of using pernicious drinks." So wrote physician John Hamett in the London Medical Gazette - describing not modern teenagers, but rather the people within nineteenth-century society who were thought by many to cause disease. 'Putrid effluvia', 'foul personal habits' and 'noxious miasmas' were held liable for sickness until the late 1800s. And from the seventeenth century, maps of outbreaks were used as tools in debates - with clusters of cases in the poorest, smelliest or lowest parts of town apparently confirming suspicions that the disease in question was caused by poor people, sewage or altitude.

In Disease Maps, medical geographer Tom Koch tours the history of disease mapping, focusing on plague, yellow fever, cancer and cholera. He explains how maps of each have both increased our understanding of epidemiology and fuelled now-discredited theories. Mapping techniques have advanced hugely - today's surveys are located using

the Global Positioning System and analysed using geographic information systems. Yet Koch's main message is that the politics, use and interpretation of spatial disease data have changed little in the past 500 years.

In a world where we can download a mobile-phone application that locates for us the nearest outbreak of Rocky Mountain spotted fever, it is easy to forget the

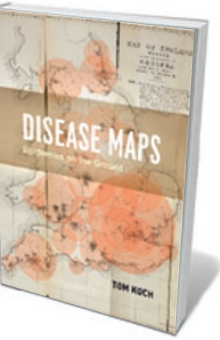

Disease Maps: Epidemics On the Ground

$\mathrm{TOM} \mathrm{KOCH}$

University of Chicago Press: $2011.368 \mathrm{pp}$ $\$ 45, £ 29$ poor understanding of pathogens we once had. In the late seventeenth century, a good 200 years before bacteria and viruses were properly understood, it was thought that there were many 'plagues' - a sickness that appeared only in warm seasons; another that was caused by noxious smells from slums; and others that moved from city to city with ships and travellers. Disease maps were drawn up but generally proved inconclusive.

Such uncertainty lingers on in scientific debates over the socioeconomic drivers of epidemic spread, or the effects of climate change on vector-borne diseases such as malaria. Disease mapping has allowed us to detect potential sociological or environmental reasons for outbreaks through their spatial association. However, maps are easily misinterpreted because of the challenge of untangling correlation and causation. The book is strewn with examples of outbreaks that have been found to cluster with a particular factor, leading to claims of an ultimately unfounded causal link. Such was the case for cholera, until one of the most famous disease-mapping studies was undertaken.

John Snow's plotting of the 1854 Broad Street cholera outbreak in London suggested the waterborne nature of the disease. His halting of the epidemic by removing the handle of the water

\section{DNATURE,COM} Old Islamic maps of science:

go.nature.com/qdzjlh 
pump around which the cases clustered is a popular tale, but Koch reveals that the conventional version is oversold. Snow's idea on the waterborne transmission of cholera was later proved correct, but his work, and that of many other mappers of the time, merely revealed the conditions in which cholera thrived, not that it is caused by a bacterium, Vibrio cholerae.

Other cholera case studies in the book include an 1831 continental-scale metaanalysis of the outbreaks that spread across Europe in the early nineteenth century - a forerunner of modern large-scale mapping projects. Koch highlights colonial Indian maps of cholera spread that were of limited use because 'natives' were not included, and London neighbourhood mapping battles that aimed to prove all kinds of transmission mechanisms. Each contains lessons for today.

Disease Maps is well researched, and packed with beautifully reproduced epidemiological maps and colourful tales of the arguments and insights each one sparked. Yet it skirts recent advances in our knowledge of disease spread. There is no mention of the state-of-the-art tools "According that could have settled to London's some of the historical 1667 bill of debates.

mortality, 11 people were killed by itches and one died from fainting in the bath."

Developments include new phylogeographic techniques for reconstructing spatial and temporal evolutionary histories of the spread of pathogens such as influenza, and Bayesian statistical models for generating uncertainty maps to accompany those charting endemic diseases such as malaria. Mobile-phone data are also providing unprecedented opportunities for exploring short-term spatial epidemiological dynamics by tracking human travel patterns.

At a time when resources are flowing into the fields of health metrics and epidemiological mapping, Disease Maps shows that some things never change. The epidemic drivers of increased trade, rapid urbanization, inequalities and civil unrest are as strong today as they were during the seventeenth-century outbreaks of plague. Koch's book takes us back to the dawn of disease statistics and mapping, when - according to London's 1667 bill of mortality - 11 people were killed by itches, one person died from fainting in the bath and many more perished when their stomachs simply 'stopped'.

Andy Tatem is an assistant professor at the Emerging Pathogens Institute and in the Department of Geography of the University of Florida, Gainesville 32610, USA. e-mail:andy.tatem@gmail.com

\section{Books in brief}

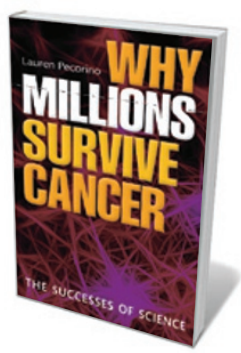

Why Millions Survive Cancer: The Successes of Science

Lauren Pecorino OXFORD UNIVERSITY PRESS 256 pp. £16.99 (2011)

One in three of us can expect to have cancer during our lifetimes.

But the prognosis is good, according to molecular biologist Lauren Pecorino. More people are surviving as better treatments come on line, thanks to advances in science and medicine. Relating the latest scientific evidence, she details for the general reader how models of cancer and knowledge of how the body defends itself against tumours have improved, and shows how the disease is better managed today. The book also examines the science that lies behind various lifestyle factors that contribute to cancer risks.

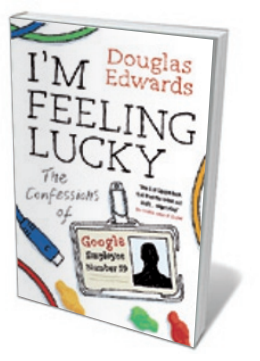

I'm Feeling Lucky: The Confessions of Google Employee Number 59 Douglas Edwards ALLEN LANE 432 pp. £20 (2011)

Douglas Edwards was Google's first director of marketing and brand management - employee number 59 — a post he held from 1999 to 2005. In his book he offers a peek inside the Googleplex, giving an intimate portrayal of the innovative company's unique culture and how it developed. He describes how the firm's founding duo, Larry Page and Sergey Brin, have encouraged a non-hierarchical management structure and fostered a creative ethos. He also gives sage management advice, explaining, for example, why you should always hire someone smarter than yourself.

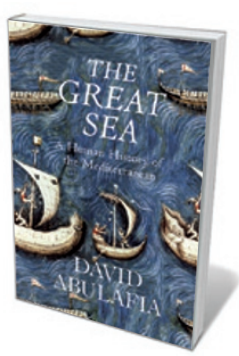

The Great Sea: A Human History of the Mediterranean

David Abulafia AlLEN LANE 816 pp. $£ 30$ (2011)

The Mediterranean Sea has witnessed the meeting of many civilizations throughout history. In this magnum opus, historian David Abulafia tells the tales of the diverse peoples that have lived around the Great Sea, portraying their trade and battles and emphasizing their varied languages and societies. From the Trojan Wars in the eleventh or twelfth centuries BC to the Grand Tours of the nineteenth century AD, and from the history of piracy to the spread of religions and modern tourism, he paints the Mediterranean as an epicentre of human history.

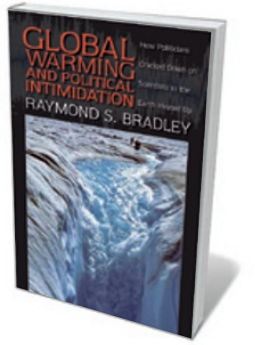

Global Warming and Political Intimidation: How Politicians Cracked Down on Scientists As the Earth Heated Up Raymond S. Bradley UNIVERSITY OF MASSACHUSETTS PRESS 168 pp. $\$ 19.95$ (2011)

In 2005, US-based climate scientist Raymond Bradley found himself in the middle of a political maelstrom. Sceptical congressmen demanded that he and his co-authors, who had published the famous 'hockey stick' graph of rising atmospheric carbon dioxide levels, hand over their data and declare their funding sources. Bradley relates this troubling episode and expresses his concern that some politicians are seeking to suppress climate science.

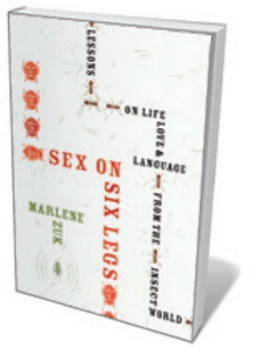

Sex on Six Legs: Lessons on Life, Love and Language from the Insect World

Marlene Zuk Houghton Mifflin HARCOURT 272 pp. \$25 (2011) Most people recoil from creepy crawlies; biologist Marlene Zuk explains their scientific allure in her latest book. She relates that insects are more numerous than any other type of animal, accounting for $80 \%$ of species. And she describes how flies, ants, wasps and their ilk mate, care for their offspring, hunt and defend themselves. Her entertaining, no-nonsense prose is packed with colourful examples. 